\title{
Estudo da degradação da força gerada por elásticos ortodônticos sintéticos
}

\author{
Fabiana Ballete de Cara Araujo*, Weber José da Silva Ursi**
}

\begin{abstract}
Resumo
Objetivo: analisar separada e comparativamente cinco marcas comerciais de elásticos sintéticos (Morelli, Ormco, GAC, TP e Unitek) quanto à degradação da força gerada por estes em função do tempo, quando mantidos continuamente estirados em uma distância de $20 \mathrm{~mm}$. Metodologia: as leituras das quantidades de força gerada pelos elásticos foram feitas nos intervalos 1/2, 1, 6, 12, 24, 48 horas; 7, 14, 21 e 28 dias. Construiu-se um gráfico de força versus tempo, onde se pôde observar significativa redução na quantidade de força liberada pelos elásticos na primeira hora de ativação. Resultados: verificou-se uma redução na quantidade de força gerada pelos elásticos de 20,31 a 38,47\% na primeira hora de testes e de 47,7 a $75,95 \%$ em 28 dias de estiramento constante. Conclusões: concluiu-se que todas as amostras das marcas comerciais estudadas sofreram significativa redução na quantidade de força liberada na primeira hora de ativação e que a média de força gerada em 21 e 28 dias de testes foi semelhante para todas as amostras pesquisadas.
\end{abstract}

Palavras-chave: Elásticos. Elastômeros. Cadeias elastoméricas.

\section{INTRODUÇÃO}

O tratamento ortodôntico corretivo consiste na transmissão de forças mecânicas aos dentes, com o intuito de movimentá-los para uma posição adequada. Assim, os materiais elásticos são considerados importantes fontes de força na movimentação ortodôntica, juntamente com as molas e as alças.

Os elásticos sintéticos começaram a ser produzidos na década de vinte, por petroquímicas, e sua utilização na Ortodontia se difundiu a partir da década de $60^{3}$. Encontram sua maior aplicação nos mecanismos fixos aos dentes, onde são usados para mover estes elementos ao longo do $\operatorname{arco}^{16}$. São indicados no fechamento de diastemas e espaços de extrações, em correções de rotações e na fixação do arco aos braquetes, como substituto das ligaduras metálicas.

No entanto, os elásticos sintéticos não podem ser considerados materiais elásticos ideais, pois são sensiveis à exposição prolongada à água, às enzimas e também às variações de temperatura ${ }^{3}$. Além disso, sofrem significante degradação na quantidade de força liberada ao longo do tempo de utilização.

Vários estudos ${ }^{1,2,3,5,6,12,14,15,16,18,19,20}$ avaliaram a degradação da força liberada pelos elásticos sintéticos, em função do tempo de estiramento a que foram submetidos, e observaram que a maior redução na quantidade de carga gerada pelos elásticos ocorreu na primeira hora de testes, em média $30 \%$.

* Doutoranda em Odontologia Restauradora pela Faculdade de Odontologia de São José dos Campos - UNESP.

** Mestre e Doutor em Ortodontia pela Faculdade de Odontologia de Bauru- USP. 
Por este motivo, recomenda-se a aplicação de força inicial maior que a desejada para uma dada movimentação ortodôntica, visando sanar tamanha redução de força ao longo do uso contínuo dos elásticos².

Por outro lado, alguns autores ${ }^{3}$ ressaltaram a importância da simulação da movimentação dentária durante os testes de degradação de força dos elásticos. Para tanto, promoveram diminuição na quantidade de estiramento ao longo do tempo, e como resultados observaram uma maior redução na quantidade de força gerada pelos elásticos em 4 semanas de avaliações, em comparação com os testes estáticos.

A influência do meio também foi avaliada sobre o comportamento dos elásticos quando mantidos continuamente estirados. Vários trabalhos ${ }^{1,4,6,7,15}$ mostraram que os elásticos quando testados em meio úmido sofreram maior degradação de força ao longo do tempo do que quando testados em meio seco. A elevação da temperatura foi considerada um fator agravante na redução de carga gerada pelos elásticos ${ }^{7,15}$. Assim , muitos estudos ${ }^{2,3,4,7,18}$ foram realizados em meio aquoso a $37^{\circ} \mathrm{C}$, simulando as condições bucais. Contudo, autores ${ }^{18}$ mostraram que a saliva artificial é o único meio que afeta significantemente todos os elastômeros, com alto ou baixo módulo de elasticidade.

Portanto, a resultante de força promovida pelos elásticos sintéticos, em um dado momento, depende da magnitude inicial da força, tempo decorrido desde a ativação e a média de decréscimo de força ${ }^{4}$.

Por este motivo, a escolha correta dos elásticos ortodônticos e o conhecimento de suas características, assim como o monitoramento cuidadoso da quantidade de força liberada nos diferentes intervalos de tempo ${ }^{13}$, são imprescindíveis para a realização segura e satisfatória do tratamento ortodôntico. Desse modo, o objetivo deste trabalho foi avaliar a quantidade de força gerada por cinco marcas comerciais de elásticos ortodônticos sintéticos em função do tempo de estiramento a que foram submetidos.

\section{MATERIAL E MÉTODO}

Adquiriram-se os elásticos ortodônticos em embalagens seladas e dentro do prazo de validade. Foram analisadas dez amostras, escolhidas aleatoriamente, de cada uma das marcas comerciais de elásticos sintéticos que podem ser observadas no quadro 1 e figura 1 .

Confeccionaram-se 5 placas em alumínio com espessura de $3,2 \mathrm{~mm}$, comprimento de $14,5 \mathrm{~mm}$ e largura de $40 \mathrm{~mm}$. Cada uma das placas foi dividida, de modo que em seu comprimento foram feitas dez marcações alinhadas, que distaram entre si $15 \mathrm{~mm}$, restando $5 \mathrm{~mm}$ em cada uma das suas margens externas. As placas também receberam marcações alinhadas na sua largura, distando entre si $20 \mathrm{~mm}$.

As placas foram então perfuradas, nas marcações anteriormente realizadas, e adaptaram-se pinos metálicos em cada um destes orifícios, obtidos a partir de tachinhas, marca comercial São Paulo $\mathrm{n}^{\circ} 4$, que tiveram suas extremidades cortadas,

\begin{tabular}{cccc}
\hline $\mathbf{t}$ & tipo & cor & referência \\
\hline Morelli & médio & cinza & 60.05 .511 \\
Ormco & médio & cinza & 639.001 \\
GAC & médio & cinza & 34.023 .88 \\
TP & médio & cinza & 384.050 \\
Unitek & médio & cinza & 3903.601 \\
\hline
\end{tabular}

Quadro 1 - Marcas comerciais dos elásticos sintéticos estudados.

\begin{tabular}{|c|c|}
\hline MORELLI & $\infty 00$ \\
\hline ORMCO & $\infty 000$ \\
\hline GAC & $\infty 00$ \\
\hline TP & $\infty \infty 0$ \\
\hline UNITEK & $\infty \infty 0$ \\
\hline
\end{tabular}

FIGURA 1 - Amostras de elásticos sintéticos. 


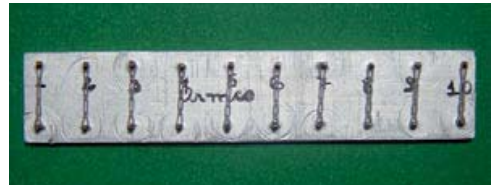

FIGURA 2 - Placa de alumínio utilizada para a fixação dos elásticos ortodônticos.

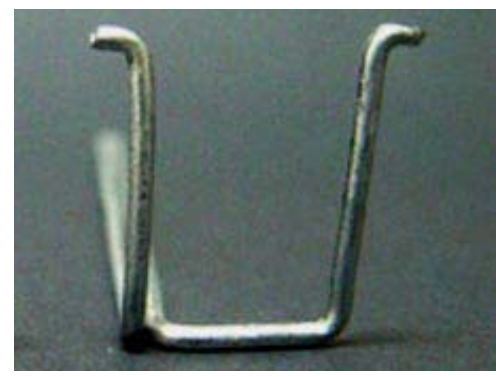

FIGURA 3 - Pinça utilizada na transferência dos elásticos.

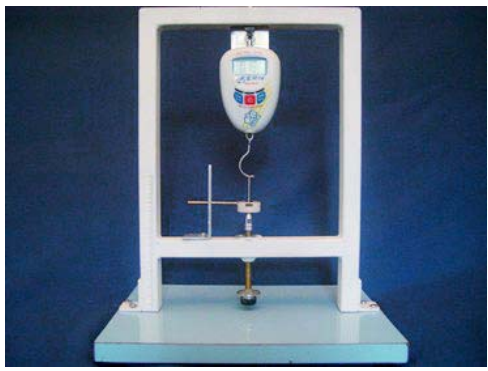

FIGURA 4 - Dispositivo posicionador do dinamômetro. obtendo-se um comprimento de $8 \mathrm{~mm}$, como pode ser observado na figura 2.

A determinação da quantidade de estiramento dos elásticos $(20 \mathrm{~mm})$ corresponde à distância entre a face mesial de um braquete colado na face vestibular de um canino superior até a face distal de um braquete colado à face vestibular de um segundo pré-molar superior, do mesmo lado do arco, quando da extração terapêutica do primeiro pré-molar superior.

Cada placa foi identificada com o nome comercial do fabricante do elástico e as amostras foram numeradas de um a dez. Antes do início dos experimentos, fez-se o pré-aquecimento da saliva artificial, Saliform ${ }^{\oplus}$, a $37^{\circ} \mathrm{C} \pm 1^{\circ} \mathrm{C}$, com auxílio de uma estufa bacteriológica da marca Farbe ${ }^{\circledR}$, modelo 119.

Cada uma das amostras, compostas por 4 elos, foi inicialmente aferida, sendo levada com o auxílio de uma pinça, de abertura constante em $20 \mathrm{~mm}$ (Fig. 3), para leitura em um dinamômetro digital da marca Kern ${ }^{\circledR}$, tipo MH5K5 com capacidade para $5 \mathrm{Kg}$ e graduado de 5 em 5 gramas, fixado em um dispositivo criado para a sua adaptação (Fig. 4). Aguardaram-se 5 segundos antes do registro da quantidade de carga, de modo a se permitir a esta-

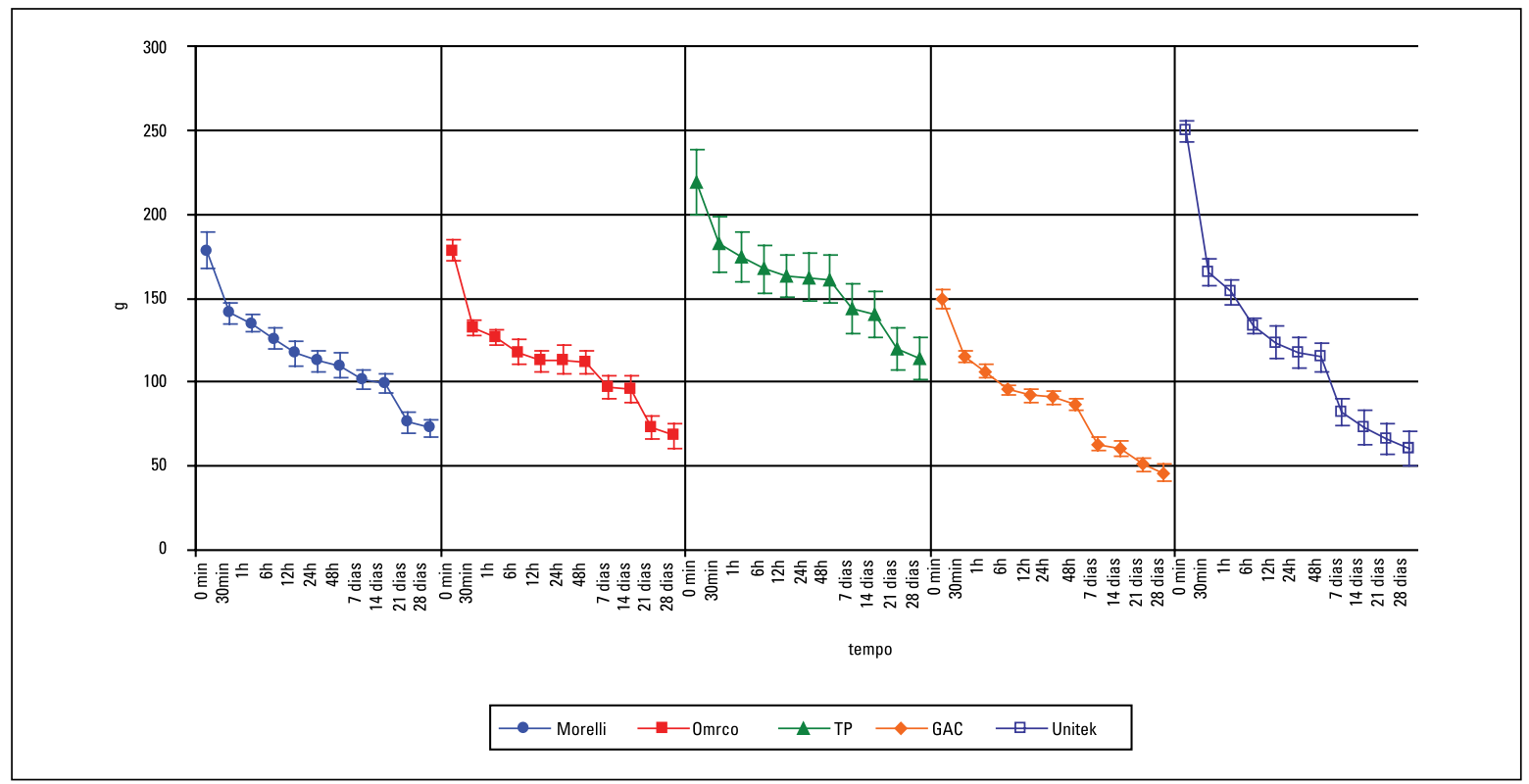

GRÁFICO 1 - Médias de tensão $x$ tempo para elásticos sintéticos. 
Tabela 1 - Percentual de redução de força em função do tempo de ativação dos elásticos sintéticos.

\begin{tabular}{cccccc}
\hline tempo & Morelli & Ormco & TP & GAC & Unitek \\
\hline 30min & $21,0 \%$ & $25,7 \%$ & $16,89 \%$ & $22,8 \%$ & $33,86 \%$ \\
1h & $24,3 \%$ & $29,1 \%$ & $20,31 \%$ & $28,5 \%$ & $38,47 \%$ \\
6h & $29,4 \%$ & $33,89 \%$ & $23,5 \%$ & $35,9 \%$ & $46,49 \%$ \\
12h & $34,4 \%$ & $36,97 \%$ & $25,57 \%$ & $38,25 \%$ & $50,50 \%$ \\
24h & $36,9 \%$ & $36,0 \%$ & $25,79 \%$ & $38,92 \%$ & $52,90 \%$ \\
48h & $38,3 \%$ & $37,5 \%$ & $26,48 \%$ & $41,94 \%$ & $53,9 \%$ \\
7 dias & $43,1 \%$ & $45,65 \%$ & $34,47 \%$ & $57,7 \%$ & $67,13 \%$ \\
14 dias & $44,2 \%$ & $46,21 \%$ & $35,84 \%$ & $59,3 \%$ & $70,74 \%$ \\
21 dias & $57,4 \%$ & $59,10 \%$ & $45,43 \%$ & $65,77 \%$ & $73,54 \%$ \\
28 dias & $59,3 \%$ & $61,9 \%$ & $47,7 \%$ & $69,12 \%$ & $75,95 \%$ \\
\hline
\end{tabular}

bilização da força para todas as amostras.

Após a leitura inicial, cada um dos elásticos foi retirado do dinamômetro, com ajuda da pinça anteriormente citada, e levado para os seus respectivos pinos de assentamento, na placa de alumínio. Os conjuntos (placa-pinos + elásticos) foram imersos em saliva artificial a $37^{\circ} \mathrm{C}$ e levados para a estufa bacteriológica. Nos intervalos de tempo $1 / 2,1,6,12,24,48$ horas; $7,14,21$ e 28 dias as placas foram retiradas da saliva artificial e colocadas sobre papel absorvente e, com o auxílio da pinça, os elásticos foram levados para aferição no dinamômetro.

\section{RESULTADOS}

A existência de diferença significativa entre os perfis de evolução dos elásticos ao longo do tempo foi verificada por meio de Análise de Variância para medidas repetidas, a qual considerou que o mesmo elástico foi examinado várias vezes. Por meio dos níveis descritivos, observou-se que a interação entre as marcas e o tempo foi significativa.

Realizou-se também uma Comparação Múltipla pelo método de Tukey, comparando todas as marcas em todos os tempos, para descobrir em quais momentos houve diferença estatisticamente significante.

A análise do gráfico 1 revelou que os elásti-
Tabela 2 - Médias e desvios-padrão para a tensão dos elásticos sintéticos em função do tempo.

\begin{tabular}{cccccc}
\hline tempo & Morelli & Ormco & TP & GAC & Unitek \\
\hline Omin & $178,5(11,3)$ & $178,5(6,7)$ & $219,0(19,7)$ & $149,0(5,7)$ & $249,5(6,0)$ \\
30min & $141,0(6,1)$ & $132,5(4,9)$ & $182,0(17,0)$ & $115,0(3,3)$ & $165,0(7,8)$ \\
1h & $135,0(5,3)$ & $126,5(4,7)$ & $174,5(15,0)$ & $106,5(4,1)$ & $153,5(7,5)$ \\
6h & $126,0(6,1)$ & $118,0(7,5)$ & $167,5(14,4)$ & $95,5(2,8)$ & $133,5(4,7)$ \\
12h & $117,0(7,1)$ & $112,5(6,3)$ & $163,0(13,0)$ & $92,0(4,2)$ & $123,5(9,4)$ \\
24h & $112,5(5,9)$ & $113,0(8,6)$ & $162,5(13,8)$ & $91,0(3,9)$ & $117,5(8,9)$ \\
48h & $110,0(7,8)$ & $111,5(7,1)$ & $161,0(14,3)$ & $86,5(3,4)$ & $115,0(8,5)$ \\
7 dias & $101,5(5,8)$ & $97,0(6,7)$ & $143,5(14,7)$ & $63,0(4,2)$ & $82,0(8,2)$ \\
14 dias & $99,5(5,5)$ & $96,0(7,7)$ & $140,5(14,0)$ & $60,5(5,0)$ & $73,0(10,3)$ \\
21 dias & $76,0(6,6)$ & $73,0(6,7)$ & $119,5(12,6)$ & $51,0(3,9)$ & $66,0(8,8)$ \\
28 dias & $72,5(5,4)$ & $68,0(7,1)$ & $114,5(12,6)$ & $46,0(5,2)$ & $60,0(10,3)$ \\
total & $115,4(29,5)$ & $111,5(29,5)$ & $158,9(31,4)$ & $86,9(29,6)$ & $121,7(53,3)$ \\
\hline
\end{tabular}

cos sintéticos da marca Unitek apresentaram a maior média de força inicial $(249,5 \mathrm{~g})$, seguida dos módulos elastoméricos da TP $(219,0 \mathrm{~g})$, Ormco e Morelli $(178,5 \mathrm{~g})$ e GAC $(149,0 \mathrm{~g})$. Por outro lado, as cadeias elastoméricas da TP geraram a maior média final de tensão, ao longo de 28 dias de experimentos $(114,5 \mathrm{~g})$, acompanhadas das amostras da marca Morelli (72,5g), Ormco (68,0g), Unitek $(60,0 \mathrm{~g})$ e GAC $(46,0 \mathrm{~g})$.

As amostras da marca comercial Unitek apresentaram maior percentual de redução na quantidade de força gerada em 28 dias de testes (75, 95\%), seguidas pelos espécimes da GAC $(69,12 \%)$, Ormco (61,9\%), Morelli (59,3\%) e TP $(47,7 \%)$ (Tab. 1, 2).

Todas as amostras das diferentes marcas comerciais avaliadas sofreram significante redução nos valores de força média num período de $1 \mathrm{~h}$ de estiramento constante, variando entre $40 \mathrm{~g}$ e $50 \mathrm{~g}$. A partir deste momento, as médias de força se estabilizaram e diminuíram gradativamente ao longo do tempo, com exceção das cadeias sintéticas da marca Unitek, que apresentaram inicialmente uma força média elevada, seguida de uma brusca queda neste valor, diferentemente das demais marcas. 
Tabela 3 - Níveis descritivos para comparação múltipla pelo método de Tukey - tensão dos elastômeros sintéticos da marca Morelli.

\begin{tabular}{|c|c|c|c|c|c|c|c|c|c|c|c|}
\hline & Omin & $30 \mathrm{~min}$ & 1h & $6 h$ & $12 \mathrm{~h}$ & $24 \mathrm{~h}$ & $48 \mathrm{~h}$ & 7 dias & 14 dias & 21 dias & 28 dias \\
\hline $30 \mathrm{~min}$ & 0,0001 & & 0,7852 & 0,0001 & 0,0001 & 0,0001 & 0,0001 & 0,0001 & 0,0001 & 0,0001 & 0,0001 \\
\hline 1h & 0,0001 & 0,7852 & & 0,0184 & 0,0001 & 0,0001 & 0,0001 & 0,0001 & 0,0001 & 0,0001 & 0,0001 \\
\hline $6 h$ & 0,0001 & 0,0001 & 0,0184 & & 0,0184 & 0,0001 & 0,0001 & 0,0001 & 0,0001 & 0,0001 & 0,0001 \\
\hline $48 \mathrm{~h}$ & 0,0001 & 0,0001 & 0,0001 & 0,0001 & 0,3772 & 1,0000 & & 0,0460 & 0,0007 & 0,0001 & 0,0001 \\
\hline 7 dias & 0,0001 & 0,0001 & 0,0001 & 0,0001 & 0,0001 & 0,0002 & 0,0460 & & 1,0000 & 0,0001 & 0,0001 \\
\hline 14 dias & 0,0001 & 0,0001 & 0,0001 & 0,0001 & 0,0001 & 0,0001 & 0,0007 & 1,0000 & & 0,0001 & 0,0001 \\
\hline
\end{tabular}

Tabela 4 - Níveis descritivos para comparação múltipla pelo método de Tukey - tensão dos elastômeros sintéticos da marca Ormco.

\begin{tabular}{|c|c|c|c|c|c|c|c|c|c|c|c|}
\hline & Omin & $30 \mathrm{~min}$ & 1h & $6 \mathrm{~h}$ & $12 \mathrm{~h}$ & $24 \mathrm{~h}$ & $48 \mathrm{~h}$ & 7 dias & 14 dias & 21 dias & 28 dias \\
\hline Omin & & 0,0001 & 0,0001 & 0,0001 & 0,0001 & 0,0001 & 0,0001 & 0,0001 & 0,0001 & 0,0001 & 0,0001 \\
\hline $30 \mathrm{~min}$ & 0,0001 & & 0,7852 & 0,0001 & 0,0001 & 0,0001 & 0,0001 & 0,0001 & 0,0001 & 0,0001 & 0,0001 \\
\hline $6 h$ & 0,0001 & 0,0001 & 0,0460 & & 0,9216 & 0,9822 & 0,5853 & 0,0001 & 0,0001 & 0,0001 & 0,0001 \\
\hline $12 \mathrm{~h}$ & 0,0001 & 0,0001 & 0,0001 & 0,9216 & & 1,0000 & 1,0000 & 0,0001 & 0,0001 & 0,0001 & 0,0001 \\
\hline $48 \mathrm{~h}$ & 0,0001 & 0,0001 & 0,0001 & 0,5853 & 1,0000 & 1,0000 & & 0,0001 & 0,0001 & 0,0001 & 0,0001 \\
\hline 7 dias & 0,0001 & 0,0001 & 0,0001 & 0,0001 & 0,0001 & 0,0001 & 0,0001 & & 1,0000 & 0,0001 & 0,0001 \\
\hline 14 dias & 0,0001 & 0,0001 & 0,0001 & 0,0001 & 0,0001 & 0,0001 & 0,0001 & 1,0000 & & 0,0001 & 0,0001 \\
\hline 21 dias & 0,0001 & 0,0001 & 0,0001 & 0,0001 & 0,0001 & 0,0001 & 0,0001 & 0,0001 & 0,0001 & & 0,9822 \\
\hline
\end{tabular}

Tabela 5 - Níveis descritivos para comparação múltipla pelo método de Tukey - tensão dos elastômeros sintéticos da marca TP.

\begin{tabular}{|c|c|c|c|c|c|c|c|c|c|c|c|}
\hline & $0 \mathrm{~min}$ & $30 \mathrm{~min}$ & 1h & $6 h$ & 12h & 24h & 48h & 7 dias & 14 dias & 21 dias & 28 dias \\
\hline $0 \min$ & & 0,0001 & 0,0001 & 0,0001 & 0,0001 & 0,0001 & 0,0001 & 0,0001 & 0,0001 & 0,0001 & 0,0001 \\
\hline 30min & 0,0001 & & 0,2113 & 0,0001 & 0,0001 & 0,0001 & 0,0001 & 0,0001 & 0,0001 & 0,0001 & 0,0001 \\
\hline 1h & 0,0001 & 0,2113 & & 0,3772 & 0,0001 & 0,0001 & 0,0001 & 0,0001 & 0,0001 & 0,0001 & 0,0001 \\
\hline $6 \mathrm{~h}$ & 0,0001 & 0,0001 & 0,3772 & & 0,9978 & 0,9822 & 0,5853 & 0,0001 & 0,0001 & 0,0001 & 0,0001 \\
\hline 12h & 0,0001 & 0,0001 & 0,0001 & 0,9978 & & 1,0000 & 1,0000 & 0,0001 & 0,0001 & 0,0001 & 0,0001 \\
\hline 24h & 0,0001 & 0,0001 & 0,0001 & 0,9822 & 1,0000 & & 1,0000 & 0,0001 & 0,0001 & 0,0001 & 0,0001 \\
\hline 48h & 0,0001 & 0,0001 & 0,0001 & 0,5853 & 1,0000 & 1,0000 & & 0,0001 & 0,0001 & 0,0001 & 0,0001 \\
\hline 7 dias & 0,0001 & 0,0001 & 0,0001 & 0,0001 & 0,0001 & 0,0001 & 0,0001 & & 1,0000 & 0,0001 & 0,0001 \\
\hline 14 dias & 0,0001 & 0,0001 & 0,0001 & 0,0001 & 0,0001 & 0,0001 & 0,0001 & 1,0000 & & 0,0001 & 0,0001 \\
\hline 21 dias & 0,0001 & 0,0001 & 0,0001 & 0,0001 & 0,0001 & 0,0001 & 0,0001 & 0,0001 & 0,0001 & & 0,9822 \\
\hline 28 dias & 0,0001 & 0,0001 & 0,0001 & 0,0001 & 0,0001 & 0,0001 & 0,0001 & 0,0001 & 0,0001 & 0,9822 & \\
\hline
\end{tabular}


Tabela 6 - Níveis descritivos para comparação múltipla pelo método de Tukey - tensão dos elastômeros sintéticos da marca GAC.

\begin{tabular}{|c|c|c|c|c|c|c|c|c|c|c|c|}
\hline & $0 \min$ & $30 \mathrm{~min}$ & 1h & $6 \mathrm{~h}$ & $12 \mathrm{~h}$ & 24h & 48h & 7 dias & 14 dias & 21 dias & 28 dias \\
\hline $0 \min$ & & 0,0001 & 0,0001 & 0,0001 & 0,0001 & 0,0001 & 0,0001 & 0,0001 & 0,0001 & 0,0001 & 0,0001 \\
\hline $30 \mathrm{~min}$ & 0,0001 & & 0,0460 & 0,0001 & 0,0001 & 0,0001 & 0,0001 & 0,0001 & 0,0001 & 0,0001 & 0,0001 \\
\hline 1h & 0,0001 & 0,0460 & & 0,0002 & 0,0001 & 0,0001 & 0,0001 & 0,0001 & 0,0001 & 0,0001 & 0,0001 \\
\hline $6 \mathrm{~h}$ & 0,0001 & 0,0001 & 0,0002 & & 1,0000 & 0,9978 & 0,0184 & 0,0001 & 0,0001 & 0,0001 & 0,0001 \\
\hline 12h & 0,0001 & 0,0001 & 0,0001 & 1,0000 & & 1,0000 & 0,9216 & 0,0001 & 0,0001 & 0,0001 & 0,0001 \\
\hline 24h & 0,0001 & 0,0001 & 0,0001 & 0,9978 & 1,0000 & & 0,9978 & 0,0001 & 0,0001 & 0,0001 & 0,0001 \\
\hline 48h & 0,0001 & 0,0001 & 0,0001 & 0,0184 & 0,9216 & 0,9978 & & 0,0001 & 0,0001 & 0,0001 & 0,0001 \\
\hline 7 dias & 0,0001 & 0,0001 & 0,0001 & 0,0001 & 0,0001 & 0,0001 & 0,0001 & & 1,0000 & 0,0001 & 0,0001 \\
\hline 14 dias & 0,0001 & 0,0001 & 0,0001 & 0,0001 & 0,0001 & 0,0001 & 0,0001 & 1,0000 & & 0,0067 & 0,0001 \\
\hline 21 dias & 0,0001 & 0,0001 & 0,0001 & 0,0001 & 0,0001 & 0,0001 & 0,0001 & 0,0001 & 0,0067 & & 0,9822 \\
\hline 28 dias & 0,0001 & 0,0001 & 0,0001 & 0,0001 & 0,0001 & 0,0001 & 0,0001 & 0,0001 & 0,0001 & 0,9822 & \\
\hline
\end{tabular}

Tabela 7 - Níveis descritivos para comparação múltipla pelo método de Tukey - tensão dos elastômeros sintéticos da marca Unitek.

\begin{tabular}{|c|c|c|c|c|c|c|c|c|c|c|c|}
\hline & $0 \mathrm{~min}$ & 30min & 1h & $6 \mathrm{~h}$ & 12h & 24h & $48 \mathrm{~h}$ & 7 dias & 14 dias & 21 dias & 28 dias \\
\hline Omin & & 0,0001 & 0,0001 & 0,0001 & 0,0001 & 0,0001 & 0,0001 & 0,0001 & 0,0001 & 0,0001 & 0,0001 \\
\hline $30 \mathrm{~min}$ & 0,0001 & & 0,0001 & 0,0001 & 0,0001 & 0,0001 & 0,0001 & 0,0001 & 0,0001 & 0,0001 & 0,0001 \\
\hline 1h & 0,0001 & 0,0001 & & 0,0001 & 0,0001 & 0,0001 & 0,0001 & 0,0001 & 0,0001 & 0,0001 & 0,0001 \\
\hline $6 \mathrm{~h}$ & 0,0001 & 0,0001 & 0,0001 & & 0,0023 & 0,0001 & 0,0001 & 0,0001 & 0,0001 & 0,0001 & 0,0001 \\
\hline $12 \mathrm{~h}$ & 0,0001 & 0,0001 & 0,0001 & 0,0023 & & 0,7852 & 0,0460 & 0,0001 & 0,0001 & 0,0001 & 0,0001 \\
\hline 24h & 0,0001 & 0,0001 & 0,0001 & 0,0001 & 0,7852 & & 1,0000 & 0,0001 & 0,0001 & 0,0001 & 0,0001 \\
\hline $48 \mathrm{~h}$ & 0,0001 & 0,0001 & 0,0001 & 0,0001 & 0,0460 & 1,0000 & & 0,0001 & 0,0001 & 0,0001 & 0,0001 \\
\hline 7 dias & 0,0001 & 0,0001 & 0,0001 & 0,0001 & 0,0001 & 0,0001 & 0,0001 & & 0,0184 & 0,0001 & 0,0001 \\
\hline 14 dias & 0,0001 & 0,0001 & 0,0001 & 0,0001 & 0,0001 & 0,0001 & 0,0001 & 0,0184 & & 0,3772 & 0,0001 \\
\hline 21 dias & 0,0001 & 0,0001 & 0,0001 & 0,0001 & 0,0001 & 0,0001 & 0,0001 & 0,0001 & 0,3772 & & 0,7852 \\
\hline 28 dias & 0,0001 & 0,0001 & 0,0001 & 0,0001 & 0,0001 & 0,0001 & 0,0001 & 0,0001 & 0,0001 & 0,7852 & \\
\hline
\end{tabular}

Tabela 8 - Níveis descritivos para comparação múltipla pelo método de Tukey - tensão dos elastômeros sintéticos no tempo inicial.

\begin{tabular}{cccccc}
\hline & Morelli & Ormco & TP & GAC & Unitek \\
\cline { 2 - 6 } Morelli & & $\mathbf{1 , 0 0 0 0}$ & 0,0001 & 0,0001 & 0,0001 \\
Ormco & $\mathbf{1 , 0 0 0 0}$ & & 0,0001 & 0,0001 & 0,0001 \\
TP & 0,0001 & 0,0001 & & 0,0001 & 0,0001 \\
GAC & 0,0001 & 0,0001 & 0,0001 & & 0,0001 \\
Unitek & 0,0001 & 0,0001 & 0,0001 & 0,0001 & \\
\hline
\end{tabular}

$\mathrm{Na}$ averiguação do perfil individual das marcas, observou-se que as cadeias elastoméricas da marca Morelli sofreram uma significativa redução na quantidade média de força liberada aos 30min de testes, ocorrendo depois uma estabilização da carga até o intervalo de $1 \mathrm{~h}$. A força novamente decresceu significantemente até o intervalo de $12 \mathrm{~h}$. Houve uma estabilização da tensão produzida pe- 
Tabela 9 - Níveis descritivos para comparação múltipla pelo método de Tukey - tensão de elastômeros sintéticos no tempo 28 dias.

\begin{tabular}{cccccc}
\hline & Morelli & Ormco & TP & GAC & Unitek \\
\cline { 2 - 6 } Morelli & & $\mathbf{0 , 9 9 7 8}$ & 0,0001 & 0,0001 & 0,0001 \\
Ormco & $\mathbf{0 , 9 9 7 8}$ & & 0,0001 & 0,0001 & $\mathbf{0 , 1 0 4 3}$ \\
TP & 0,0001 & 0,0001 & & 0,0001 & 0,0001 \\
GAC & 0,0001 & 0,0001 & 0,0001 & 0,0001 \\
Unitek & 0,0001 & $\mathbf{0 , 1 0 4 3}$ & 0,0001 & 0,0001 & \\
\hline
\end{tabular}

las cadeias sintéticas, entre os períodos de $12 \mathrm{~h}$ e 48h, e uma outra queda foi registrada no sétimo dia de experimentos, seguindo-se um período de estabilização até o intervalo de 14 dias. No $21^{\circ}$ dia de pesquisa a força média produzida pelas amostras foi significantemente menor que a gerada no intervalo de sete dias, no entanto manteve-se estável até o $28^{\circ}$ dia de testes (Tab. 3).

Os perfis individuais das marcas Ormco, TP e GAC apresentaram comportamento semelhante ao perfil individual da marca Morelli (Tab. 4, 5, 6).

No entanto, o perfil individual das amostras da marca Unitek mostrou um comportamento diferente das demais marcas comerciais pois apresentou queda constante e significativa na quantidade de força até o intervalo $12 \mathrm{~h}$. A carga ficou estável até o momento $24 \mathrm{~h}$. Novas reduções significativas foram registradas nos intervalos de sete dias e 14 dias, a partir do qual a força tornou-se estável até o término dos experimentos, ou seja, aos 28 dias de testes (Tab. 7).

Comparou-se as diferentes marcas em cada um dos tempos e observou-se que as marcas Morelli e Ormco apresentaram médias de força estatisticamente semelhantes no momento inicial da pesquisa (Tab. 8); enquanto nos intervalos de $30 \mathrm{~min}$ e $1 \mathrm{~h}$ todas as marcas produziram médias de força diferentes entre si.

Nos tempos $6 \mathrm{~h}$ e $12 \mathrm{~h}$ ocorreu igualdade estatística entre as quantidades de carga produzida pelas marcas Ormco e Morelli. Nos intervalos de tempo $24 \mathrm{~h}$ e $48 \mathrm{~h}$ houve igualdade estatística na quantidade de tensão gerada pelas amostras das marcas Morelli, Ormco e Unitek; enquanto nos tempos 7 dias e 14 dias as médias de força geradas pelas marcas Morelli e Ormco foram semelhantes entre si, e nos momentos 21 dias e 28 dias, além da igualdade anterior, observou-se semelhança estatística entre as quantidades médias de força produzidas pelas marcas Unitek e Ormco (Tab. 9).

De modo geral, averiguou-se que as marcas TP e GAC forneceram médias de força diferentes de todas as outras marcas, em todos os períodos de tempo estudados, enquanto as marcas Morelli e Ormco tiveram praticamente o mesmo perfil médio em todos os tempos.

\section{DISCUSSÃO}

Os elásticos ortodônticos são importantes fontes de transmissão de força aos dentes e, por isso, são muito usados em Ortodontia. No entanto, estes materiais não são considerados ideais, pois a força por eles gerada diminui gradativamente em função do tempo de ativação. Desse modo, vários

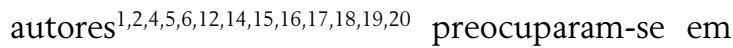
avaliar a degradação da força sofrida pelos elásticos sintéticos em função do tempo de estiramento a que foram submetidos.

O estudo destes materiais justifica-se pela sua intensa utilização na Ortodontia e pelo fato de poder ser considerado substituto dos elásticos de látex, em casos de pacientes hipersensíveis a este material $7,8,10,11$. Para tanto, todas as amostras de elásticos sintéticos foram mantidas estiradas continuamente em $20 \mathrm{~mm}$, imersas em saliva artificial a $37^{\circ} \mathrm{C}$, de acordo com alguns estudos ${ }^{1,6,7,9}$ que mostraram que a degradação da força sofrida pelos materiais elásticos sintéticos é significante- 
mente maior quando testados em meio úmido do que quando avaliados em ambiente seco. Utilizouse saliva artificial como meio de estocagem ${ }^{18}$, pois entendeu-se que ela é o único meio que afeta significantemente todos os elastômeros, inclusive os módulos elásticos com alto ou baixo módulos de elasticidade.

Manteve-se a temperatura constante em $37^{\circ} \mathrm{C}$ $\pm 1^{\circ} \mathrm{C}$, por se tratar da temperatura corpórea, e pelo fato de a temperatura ter influência significativa sobre a degradação de forças sofridas pelos elásticos sintéticos ${ }^{7,15}$. Todas as amostras de elásticos sintéticos foram transferidas da placa de testes para aferição no dinamômetro, e vice-versa, através de pinças que impediram qualquer alteração nas distâncias pré-estabelecidas ${ }^{11}$. Desse modo, durante todo o período de testes os espécimes foram mantidos estirados continuamente, de modo que pôde-se evitar o fenômeno de recuperação elástica e, conseqüentemente, obtenção de resultados falsos.

As cadeias elastoméricas sintéticas foram mantidas estendidas continuamente em $20 \mathrm{~mm}$, conforme observado na literatura ${ }^{3}$, para simular a distância entre a aleta mesial de um braquete, colado na face vestibular de um canino superior, e a aleta distal de um outro braquete, colado na face vestibular do $2^{\circ}$ pré-molar superior, do mesmo lado do arco, quando da extração terapêutica do $1^{\circ}$ pré-molar superior. Fez-se a eleição deste comprimento, pois a retração de caninos é uma manobra comum nos tratamentos ortodônticos.

As cadeias elastoméricas sintéticas foram avaliadas em um período de 28 dias, como indicado por vários trabalhos ${ }^{1,2,4,7,14,18}$, pois coincide com o período médio de troca dos elásticos sintéticos praticado pelos ortodontistas.

A força inicial média desenvolvida pelas amostras da marca comercial TP foi maior que as geradas pelas demais marcas, com exceção da marca Unitek. Este fato se deve à utilização de um menor número de elos, três no total, em comparação às demais marcas, que foram compostas por quatro elos. Tal procedimento se deveu ao fato de as cadeias elastoméricas da TP apresentarem pontes intermediárias inter-elos mais longas que as demais cadeias estudadas, de modo que se fossem utilizados quatro elos, as cadeias da TP gerariam cargas muito reduzidas em relação às demais. Assim o emprego de três elos para as amostras da TP aproximou mais o seu comprimento ao comprimento das outras amostras estudadas. Os elásticos sintéticos testados apresentaram significante queda na quantidade de força gerada após lh de ativação constante, registrando-se percentuais de redução entre $20 \%$ e $40 \%$.

Ao comparar-se os resultados deste trabalho com os demais encontrados na literatura observou-se que, na primeira hora de testes, a redução média de força sofrida pelas amostras foi menor que a encontrada em outras pesquisas ${ }^{1,5}$.

Contudo, avaliando-se os resultados ${ }^{5}$, nota-se que na primeira hora de testes houve uma redução média de $45,3 \%$ na quantidade de força gerada pelos elásticos, considerando-se quatro distâncias de estiramento das amostras (22, 28, 34 e 40mm). Porém, quando o estiramento em $22 \mathrm{~mm}$ foi considerado separadamente, a redução média de força foi de $34,87 \%$, condizente com o intervalo de resultados encontrados neste trabalho. Do mesmo modo, ao final de 3 semanas, a avaliação feita por estes autores ${ }^{5}$ mostrou uma queda na quantidade de carga de 59\%, também concordante com o intervalo de resultados mostrado nesta pesquisa.

Outro trabalho ${ }^{1}$ mostrou uma redução média de força na ordem de $46,9 \%$, maior que as médias encontradas pelo presente estudo. No entanto, as amostras avaliadas por estes pesquisadores foram estendidas em $28 \mathrm{~mm}$, em contrapartida com os experimentos apresentados, onde as amostras ficaram estiradas em $20 \mathrm{~mm}$. Por este motivo, provavelmente as amostras sofreram maior redução na quantidade de carga gerada em função do tempo, devido ao maior estiramento que sofreram.

Os experimentos realizados por Kuster et al. ${ }^{14}$ mostraram uma redução média na quantidade de 
força menor que a encontrada por esta pesquisa, provavelmente relacionado ao fato de terem realizado seus testes em meio seco.

Ao término de 28 dias de análises, observouse uma redução de $47 \%$ a $76 \%$ na quantidade de força liberada por diferentes marcas de cadeias elastoméricas sintéticas. Porém, neste trabalho não realizou-se simulação de movimentação dentária, que para alguns autores ${ }^{4}$ promove um maior percentual de redução de força em função do tempo de ativação destes materiais.

O presente trabalho mostrou valores estatisticamente significativos na quantidade de tensão dos elásticos sintéticos até o intervalo de 21 dias, contradizendo outros resultados ${ }^{1}$, o que pode estar relacionado à utilização de saliva artificial ao invés de água destilada como meio de armazenagem dos módulos plásticos.

Pôde-se observar que as amostras de elásticos sintéticos ofereceram diferentes quantidades de força inicial e final, o que torna prudente o monitoramento da quantidade de tensão gerada pelos elásticos por parte do clínico, para se atingir os resultados desejados no tratamento. No entanto, o monitoramento de cargas não é um procedimento freqüente na rotina profissional dos ortodontistas ${ }^{13}$.

\section{CONCLUSÕES}

- Todos os grupos de amostras de cadeias elastoméricas sintéticas sofreram significativa redução na quantidade de força liberada na primeira hora de ativação.

- As amostras das cadeias elastoméricas das marcas Ormco e Morelli tiveram praticamente o mesmo perfil médio de força em função dos tempos considerados.

- As amostras de elásticos sintéticos da marca Unitek mostraram maior percentual de queda na quantidade de força liberada ao final de 28 dias de testes.

- As cadeias elastoméricas da marca GAC apresentaram os menores valores médios de força inicial e final em relação às outras marcas analisadas; enquanto as amostras da marca TP apresentaram o maior valor médio de força final, em comparação com as outras marcas comerciais estudadas.

- Para todas as cadeias elastoméricas sintéticas houve igualdade estatística na quantidade de força gerada entre os intervalos de 21 e 28 dias, o que permite indicar a troca destes materiais em intervalos mensais, desde que a média de força alcançada em 21 dias seja suficiente para ainda induzir a movimentação dentária.

- Cabe ao clínico avaliar a quantidade de força necessária para cada caso em particular e julgar, com base nos resultados encontrados, qual o elástico mais indicado e qual o tempo mais apropriado para sua troca, buscando alcançar a movimentação dentária desejada.

\title{
Study of force degradation produced by synthetic orthodontic elastics
}

\begin{abstract}
Aim: to analyze five commercial brands of synthetic elastics (Morelli, Ormco, GAC, TP and Unitek), considering force degradation of these materials when maintained stretched continuously. Methods: the synthetic elastics were stretched $20 \mathrm{~mm}$ and the readings of the amount generated for elastics were done in the intervals: $1 / 2,1,6,12$, 24,48 hours; 7, 14, 21 and 28 days. Results: it was found in the first hour of activation a significant reduction on the amount of force generated for all elastics. There was a reduction in the amount of the generated force elastics of 20.31 to $38.47 \%$ in the first hour of the tests and 47.7 to $75.95 \%$ in 28 days of the activation. Conclusions: it was concluded that for the synthetic elastics the average force generated in 21 and 28 days of tests was statically similar in all samples.
\end{abstract}

Key words: Elastic. Elastomer. Elastomeric chain. 


\section{REFERÊNCIAS}

1. ASH, J. L.; NIKOLAI, R. J. Relaxation of orthodontic elastomeric chains and modules in vitro and in vivo. J Dent Res, Washington, v. 5, n. 5-6, p. 685- 90, May/June 1978.

2. BISHARA, S. E.; ANDREASEN, G. E. A comparision of time related forces between plastics alastiks and latex elastics. Angle Orthod, Appleton, v. 40, n. 4, p. 319-28, Oct. 1970.

3. DE GENOVA, D. C. et al. Force degradation of orthodontic elastomeric chains - a product comparation study. Am J Orthod Chatham, v. 87, n. 5, p. 377-84, May 1985.

4. FERRITER, J. P.; MEYERS, C. E.; LORTON, L. The effect of hidrogen ion concentration on the degradation rate of orthodontic polyurethane chain elastics. Am J Orthod Orthop, St. Louis v. 98, n. 5 , p. $404-10$, Nov. 1990

5. HERSHEY, H. G.; REYNOLDS, W. G. The plastic module as an orthodontic tooth-moving mechanism. Am J Orthod, Chatham, v. 67, n. 5, p. 555-62, May 1975.

6. HUGET, E. F. PATRICK, K. S. NUNEZ, L. J. Observation on the elastic behavior of a sintetic orthodontic elastomer. J Dent Res, Washington, v. 69, n. 2, p. 496-501, Feb. 1990.

7. HWANG, C. J.; CHA, J. Y. Mechanical and biologicalcomparasion of latex and silicone rubber bands. Am J Orthod Dent Orthop, St. Louis, v. 124, n. 4, p. 379- 86, Oct. 2003.

8. JACOBSEN, N.; HENSTEN-PETTERSEN, A. Changes in occupational health problems and adverse patient reactions in orthodontics from 1987 to 2000. Eur J Orthod, Oxford, v. 25, n. 6, p. 591-8, Dec. 2003.

9. KANCHANA, P.; GODFREY, K. Calibration of force extension and force degradation characteristics of orthodontic latex elastics. Am J Orthod Dent Orthop, St. Louis, v. 118, n. 3, p. 280- 7, Sept. 2000.
10. KERSHEY, M. L. et al. A comparison of dynamic and static testing of latex and nonlatex orthodontic elastics. Angle Orthod, Appleton, v. 72, n. 2, p. 181-6, Apr. 2003.

11. KERSHEY, M. L. et al. An in vitro comparison of 4 brands of nonlatex orthodontic elastics. Am J Orthod Dent Orthop, St. Louis, v. 123, n. 3, p. 401- 7, Sept. 2003.

12. KOVATCH, J. S. et al. Load-extension-time behavior of orthodontic alastiks. J Dent Res, Washington, v. 55, n. 5, Sept./ Oct. 1976.

13. KUROL, J. et al. Force magnitude applied by orthodontists. An inter and intra-individual study. Eur J Orthod, Oxford, v. 18, n. 1, p. 69-75, Feb. 1996

14. KUSTER, R.; INGERVALL, B.; BÜRGIN, W. Laboratory and intra -oral tests of the degradation of elastics chains. Eur J Orthod, Oxford, v. 8, n. 3, p. 202-8, Aug. 1986.

15. STEVENSON, J. S.; KUSY, R. P. Force application and decay characteristics of untreated and treated polyurethane elastomeric chains. Angle Orthod, Appleton, v. 64, n. 6, p. 455-67, Apr 1994.

16. ROCK, W. P.; WILSON, H. J.; FISHER, S. E. A laboratory investigation of orthodontic elastomeric chains. Br J Orthod, Oxford, v. 12, n. 4, p. 202-07, Oct. 1985.

17. VARNER, R. E.; BUCK, D. L. Force production and decay rate in alastiks modules. J Biomed Mat Res, New York, v. 12, n. 3 p. 361-6, Sept. 1978.

18. VON FRAUNHOFER, J. A.; COFFELT, M. T. P.; ORBELL, G. M. et al. The effects of artificial saliva and topical fluoride treatments on the degradation of the elastics properties of the orthodontics chains. Angle Orthod, Appleton, v. 62, n. 4, p. 265-74, 1992.

19. WARE, A. L. A survey of elastics for control of tooth moviment, Part 1: general properties. Aust Orthod J, Brisbane, v. 2, n. 2, p. 99-08, Feb. 1970.

20. WARE, A. L. Some properties of plastics modules used for tooth moviment. Aust Ortod J, Brisbane, v. 2, n. 5, p. 200-2, Feb. 1971
Endereço de correspondência

Fabiana Ballete de Cara Araujo

R. Dr. Ademar Nobre, 125

CEP: 02.940-140 - São Paulo/SP

E-mail: ballet.cara@ig.com.br 